500 participants in 3-weeks. Cost analysis suggested incentives might be cost-effective for screening some high risk groups. We eagerly await results of the French i-Predict trial of 6monthly chlamydia screening to reduce PID incidence over 2years in 4000 female students.

\section{S05.1 BEING ALHIV: SEXUAL AND REPRODUCTIVE HEALTH OF ADOLESCENTS AND YOUNG PEOPLE LIVING WITH HIV IN SUB-SAHARAN AFRICA}

1,2E Toska*, 'B Banougnin. 'University of Cape Town, Cape Town, South Africa; ${ }^{2}$ University of Oxford, Oxford, UK

10.1136/sextrans-2021-sti.32

Background Over three quarters of all new HIV infections among 15-24 year old adolescents and young people globally take place in sub-Saharan Africa. As this growing cohort becomes older, understanding and meeting their sexual and reproductive health $(\mathrm{SRH})$ needs is critical, particularly in light of COVID-19 healthcare and social disruptions. However, few studies have documented these outcomes among adolescents in resource-limited settings, with none reporting data from longitudinal cohorts.

Summary This talk summarises what we know about the sexual and reproductive health of adolescents living with HIV in sub-Saharan Africa, particularly experiences of pregnancy, motherhood and relationships. It draws from findings of a review of SRHR experiences of adolescents and young people living with HIV, complemented by analyses of two large community-traced cohort: the Mzantsi Wakho ('Your South Africa') and HEY BABY (Helping Empower Youth Brought up in Adversity with their Babies and Young children) studies in South Africa. The Mzantsi Wakho cohort conducted three waves of data collection with over 1,600 adolescents and young people living with HIV (93\%-97\% retained at each wave), 1,064 of whom were living with HIV since baseline. The HEY BABY study recruited over 1,000 adolescent and young women who had their first child $<20$ years old, 315 of whom were living with HIV. Qualitative data from COVID-19 related research with two Teen Advisory Groups in South Africa and Kenya will also be shared to highlight sexual and reproductive health service provision and access experiences of young people and their healthcare providers.

\section{S05.4 AMPLIFYING THE VOICES OF YOUNG PEOPLE IN GLOBAL SOUTH TO ACCESSIBLE AND AFFORDABLE SEXUAL REPRODUCTIVE HEALTH AND RIGHTS SERVICES IN THE EFFORT TO CURB STIS}

I Ogeta*. Athena Network, Nairobi, Kenya

\subsection{6/sextrans-2021-sti.33}

Background Inaccessibility of SRHR services among young people has continued to impose a huge burden of morbidity and mortality in Africa by how STIs contribute to sexual transmission of HIV infections where the AGYW have continued to face disproportionate vulnerability to acquiring HIV.

Contributing factors:

- Africa lacks systematic and comprehensive STI surveillance yet it contains a large young population that is sexually active. There is a lack of accurate Primary prevention information, education, and communication campaigns.

- The non-existence of youth-friendly SRHR programs at grassroots levels lead to delayed diagnosis and treatment among young people resulting in high rates of infection complications

- SHRH care is, unfortunately, being provided by a variety of health care providers, lacking proper training in case management, and the quality of care is often compromised

- Delay in seeking care mostly a result of the asymptomatic nature of many STIs including HIV which is highly associated with low levels of awareness of sexual health and the stigma associated with genital symptoms, and HIV treatment

Recommendations:

- Programs promoting health education should be supported and adequately resourced to allow screening to be easily available and accessible thus early infection prevention, detection, improved management, and improved access to care.

- Prevention and control should be considered as an integral part of comprehensive sexuality and reproductive health services in order to help improve SHRH and access to SRHR services among the young people and stakeholders should identify barriers to the implementation of existing tools and devise possible strategies for ensuring that effective STI control programs are implemented

Conclusion There is urgency for an effective and efficient integrated approach that is not just problem-oriented but one that provides for mitigation of risk factors and puts in place a safety net for early detection and prevention of SRH challenges including screening, prevention, and treatment services.

\section{S06.1 THE HEALTHCARE EXPERIENCES OF TRANSGENDER WOMEN LIVING WITH HIV IN THE BUFFALO CITY METRO MUNICIPALITY}

L Van Der Merwe*, A Mavhandu-Mudzusi. Social, Health and Empowerment Feminist Collective, Quigney, South Africa

10.1136/sextrans-2021-sti.34

Transgender women bear a high burden of HIV in South Africa, and are not fully engaged in healthcare across the HIV continuum of care. The aim of this study was to gain an understanding of the healthcare experiences of transgender women living with HIV in the Buffalo City Metro Municipality. The study employed an interpretative phenomenological analysis design. Twelve participants were enrolled using a snowballing sampling technique. Data was collected using semi-structured interviews and analysed using an interpretative phenomenological analysis framework. Four super-ordinate themes emerged from the data: reaction to HIV positive diagnosis, disclosure of HIV status, adherence to ART, and experiences in utilising healthcare services. The findings reveal positive and negative healthcare experiences among transgender women living with HIV in Buffalo City Metro. Participants reported a number of factors that potentiate healthcare avoidance. These include stigma at various levels in transgender women's journey to access care, as well as healthcare worker insensitivity to their unique health needs. Healthcare 